\title{
Comparison of the clinical results of surgical resection for extrahepatic cholangiocarcinomas: Hilar cholangiocarcinoma and mid-to-distal cholangiocarcinoma
}

\author{
Pyung Jung ${ }^{1}$, Eung-Ho Cho ${ }^{1}$, Sang-Bum $\mathrm{Kim}^{1}$, and Ryoung-Go Kim ${ }^{2}$ \\ Department of Surgery, ${ }^{1}$ Korean Cancer Center Hospital, Seoul, \\ ${ }^{2}$ Dongnam Institution of Radiological and Medical Science, Busan, Korea
}

\begin{abstract}
Backgrounds/Aims: Hilar cholangiocarcinomas (HLC) are known to have worse prognoses than mid-to-distal cholangiocarcinomas (CBDC). We analyzed the clinical results of surgical resections for extrahepatic cholangiocarcinomas to validate the differences in the prognoses of HLC and CBDC. Methods: Two hundred and eighty-one patients underwent curative surgical resections for extrahepatic cholangiocarcinomas at the Department of Surgery in the Korea Cancer Center Hospital. Among them, we analyzed the T2 and T3 patients and compared the clinical results between those with HLC $(n=74)$ and those with CBDC $(n=65)$. Results: The rate of R1 resections was significantly higher in the HLC patients compared to the CBDC patients $(31.1 \%$ vs $12.3 \%, p=0.006)$. The overall survival rate of the T2/T3 patients was lower in the HLC group than in the CBDC group $(24.5 \%$ vs $51.7, p=0.039)$. The recurrence-free survival rate was $23.3 \%$ in the $\mathrm{HCL}$ patients and $50.9 \%$ in the CBDC patients $(p=0.06)$. In the subgroup analysis, the survival rates were not different in patients who had lymph node metastases or in patients who underwent R1 resections between the HLC and CBDC patients. Poor independent prognostic factors for the overall and recurrence-free survival rates in the T2/T3 extrahepatic cholangiocarcinoma patients were the presence of lymph node metastases and the hilar locations of tumor. Conclusions: HLC patients had poorer prognoses than CBDC patients. However, in patients with lymph node metastases, the prognosis was poor and was not different between the HLC and CBDC patients. Other adjuvant treatment methods are needed for extrahepatic cholangiocarcinoma patients with lymph node metastases to improve their prognoses. (Ann Hepatobiliary Pancreat Surg 2019;23:319-326)
\end{abstract}

Key Words: Hilar cholangiocarcinoma; Mid-to-distal cholangiocarcinoma; Prognosis

\section{INTRODUCTION}

Cholangiocarcinomas account for approximately 3\% of all gastrointestinal malignancies, with a prevalence in autopsy studies of 0.01 to 0.46 percent. In the United States, the incidence of bile duct cancer is between one and two patients per 100,000 people and 3,500 cases occur every year. ${ }^{1}$ However, South Korea has been reported to be one of the countries with a high incidence of bile duct cancer. ${ }^{2}$ Of the 214,701 newly-registered cancer patients in 2015, patients with extrahepatic bile duct cancer ranked ninth and had the sixth highest mortality rate in South Korea. ${ }^{3}$ Cholangiocarcinomas can be classified into intrahepatic cholangiocarcinomas and extrahepatic cholangiocarcinomas according to their location. Extrahepatic cholangiocarcinoma can be further classified into hilar cholangiocarcinomas (HLC), mid-bile duct cancer, and distal bile duct cancer (CBDC). ${ }^{4,5}$ Hilar cholangiocarcinoma (HLC) involves the common hepatic duct and the confluence of the left and right hepatic duct and accounts for $60-70 \%$ of all extrahepatic cholangiocarcinomas. ${ }^{6}$ Middle-to-distal cholangiocarcinomas (CBDC) account for $20-40 \%$ of the extrahepatic cholangiocarcinomas. ${ }^{7}$

The primary treatment for cholangiocarcinoma is surgical treatment but it has been reported that only 10 to $40 \%$ of patients with cholangiocarcinomas could be resected. ${ }^{8}$ Curative surgery for cholangiocarcinoma depends on the site of tumor development. Pancreaticoduodenectomy is

Received: March 29, 2019; Revised: July 17, 2019; Accepted: July 25, 2019

Corresponding author: Eung-Ho Cho

Department of Surgery, Korean Cancer Center Hospital, 75 Nowon-ro, Nowon-gu, Seoul 01812, Korea Tel: +82-2-970-2114, Fax: +82-2-970-2419, E-mail: gsceh@kirams.re.kr

Copyright (C) 2019 by The Korean Association of Hepato-Biliary-Pancreatic Surgery

This is an Open Access article distributed under the terms of the Creative Commons Attribution Non-Commercial License (http://creativecommons.org/ licenses/by-nc/4.0) which permits unrestricted non-commercial use, distribution, and reproduction in any medium, provided the original work is properly cited. Annals of Hepato-Biliary-Pancreatic Surgery • pISSN: 2508-5778 - eISSN: 2508-5859 
usually performed for CBDC. For the resection of HCC, right or left hepatectomy and caudate lobectomy are frequently necessary, in addition to bile duct resection, depending on the extent and direction of the invasion into the liver. If radical surgery for cholangiocarcinoma is not possible, palliative surgery is considered. Several studies have reported that the prognosis for HLC was worse than that for CBDC. ${ }^{9,10}$ The possible cause of the difference is that symptoms, such as jaundice and cholangitis, develop more quickly, so can be diagnosed quickly in CBDC. The relatively higher resection rate in $\mathrm{CBDC}$ is due to the lower incidence of liver and major vessel invasions compared to HLC. ${ }^{11}$

The purpose of this study was to compare the prognosis of HLC and CBDC after curative resections in our hospital.

\section{MATERIALS AND METHODS}

\section{Patient and data collection}

From January 1990 to December 2013, 281 patients underwent surgery for extrahepatic bile duct cancer in the
Department of Surgery at the Korea Cancer Center Hospital, Seoul, South Korea. We selected T2 and T3 patients based on AJCC (American Joint Committee on Cancer, $7^{\text {th }}$ edition) criteria who successfully underwent curative resections. There were 139 patients in the study. Among the 139 patients, 74 patients had hilar cholangiocarcinoma and 65 had distal bile duct cancer.

Clinical data, including age, sex, tumor markers, transfusions, operative complications, and 90-day hospital mortality; and pathologic data, including $\mathrm{T}$ stage, $\mathrm{N}$ stage, and histological differentiation were collected for the patients retrospectively. We analyzed the clinical data and compared the survival results between the hilar cholangiocarcinoma and distal bile duct cancer groups. In addition, the prognostic factors for all 139 patients were analyzed.

This study was approved by the institutional review board of the Korea Institute of Radiological and Medical Sciences (KIRAMS) (IRB no. 2018-11-007).

The data were analyzed using IBM SPSS STATISTICS KOREAN VERSION 23, Kaplan-Meier analysis, Cox regression analysis, and chi-squared test. $p$-values less than

Table 1. Comparison of clinical and pathologic data between the hilar cholangiocarcinoma and distal bile duct cancer patients

\begin{tabular}{|c|c|c|c|c|c|}
\hline & \multicolumn{2}{|l|}{ Hilar cholangiocarcinoma $(n=74)$} & \multicolumn{2}{|l|}{ Distal bile duct cancer $(n=65)$} & \multirow{2}{*}{$\begin{array}{r}p \text { value } \\
0.336\end{array}$} \\
\hline Sex (male:female) & $43: 31$ & & $41: 24$ & & \\
\hline Age $($ mean \pm SD $)$ & $62.0 \pm 7.8$ & & $63.7 \pm 7.7$ & & 0.396 \\
\hline CA 19-9 $(\leq 40(\mathrm{U} / \mathrm{ml}): 40<)$ & $14: 51$ & & $15: 43$ & & 0.362 \\
\hline \multirow[t]{7}{*}{ Operation name } & $\begin{array}{l}\text { Right hemihepatectomy } \\
\text { ( } \pm \text { caudate lobectomy)+extra } \\
\text { hepatic bile duct resection }\end{array}$ & 29 & Pancreaticoduodenectomy & 59 & \\
\hline & $\begin{array}{l}\text { Right trisectionectomy } \\
( \pm \text { caudate lobectomy })+\text { extra } \\
\text { hepatic bile duct resection }\end{array}$ & 24 & $\begin{array}{l}\text { Extrahepatic bile duct } \\
\text { resection }\end{array}$ & 6 & \\
\hline & $\begin{array}{l}\text { Left hemihepatectomy } \\
\text { ( } \pm \text { caudate lobectomy)+extra } \\
\text { hepatic bile duct resection }\end{array}$ & 6 & & & \\
\hline & $\begin{array}{l}\text { Left trisectionectomy } \\
( \pm \text { caudate lobectomy })+\text { extra } \\
\text { hepatic bile duct resection }\end{array}$ & 5 & & & \\
\hline & Hepatopancreaticoduodenectomy & 8 & & & \\
\hline & Extrahepatic bile duct resection & 1 & & & \\
\hline & Pancreaticoduodenectomy & 1 & & & \\
\hline Curability (R0:R1) & $51: 23$ & & $57: 8$ & & 0.006 \\
\hline Transfusion (no:yes) & $41: 33$ & & $55: 10$ & & $<0.001$ \\
\hline Complication (no:yes) & $23: 50$ & & $20: 43$ & & 0.561 \\
\hline Hospital mortality, N (\%) & $4(5.4 \%)$ & & $2(3.1 \%)$ & & 0.404 \\
\hline $\mathrm{T} 2: \mathrm{T} 3$ & $41: 33$ & & $55: 10$ & & 0.179 \\
\hline Lymph node (N0: N1) & $52: 22$ & & $39: 26$ & & 0.137 \\
\hline Differentiation (well:moderate:poor) & $32: 30: 7$ & & $20: 32: 7$ & & $>0.05$ \\
\hline
\end{tabular}


0.05 were considered statistically significant.

\section{RESULTS}

Sex, age, tumor markers, operative complications, hospital mortality, T-stage, histological differentiation, and lymph node metastasis were not statistically different between the HLC and the CBDC patients. In the HLC patients, right hemihepatectomies with extrahepatic bile duct resections were performed in 29 patients, right trisectionectomies with extrahepatic bile duct resections in 24 patients, left hemihepatectomies in six patients, left trisectionectomies in five patients, hepato-pancreatico-duodenectomies in eight patients, extrahepatic bile duct resection

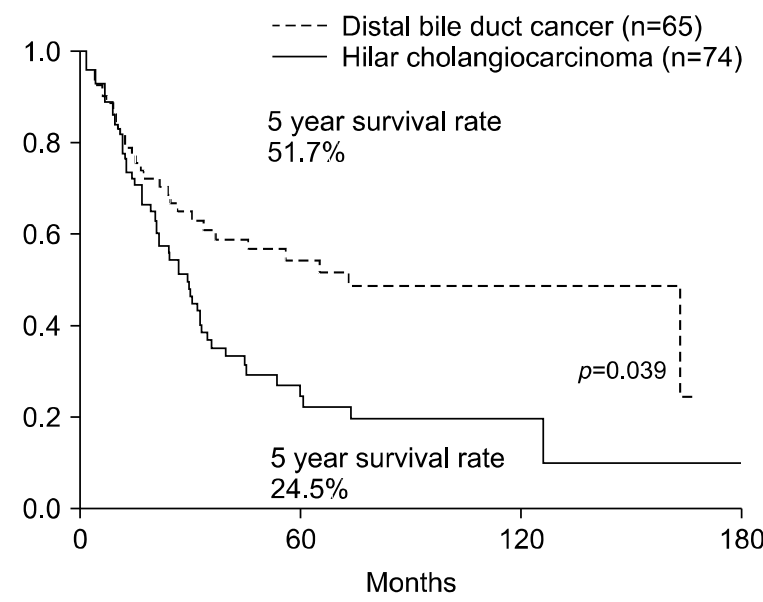

Fig. 1. Comparison of the overall-survival rates with hilar cholangiocarcinoma and distal bile duct cancer according to cancer location (T2/T3).

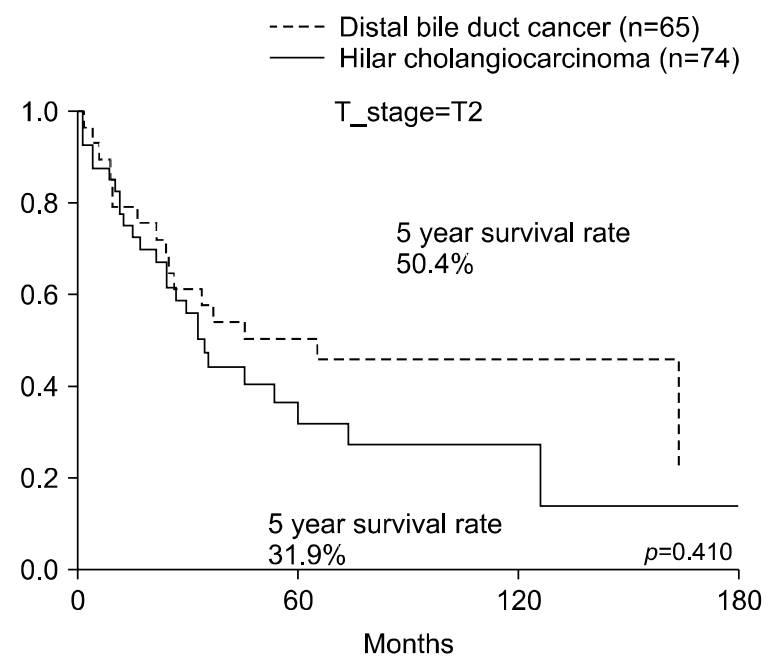

in one patient, and pancreatico-duodenectomy in one patient. In the CBDC patients, pancreatico-duodenectomies were performed in 59 patients and bile duct resections were performed in six patients (Table 1).

In the HLC patients, R1 resections were done in 23 patients (31\%) and in the CBDC patients, R1 resections were performed in eight patients (12\%). The difference between the $\mathrm{R} 1$ resection rates between the groups was statistically significant $(p=0.006)$. The 5 -year overall survival rate was $24.5 \%$ in the HLC group and $51.7 \%$ in the CBDC group. The difference between the 5 -year overall survival rates were statistically significant $(p=0.039)$ (Fig. 1). In the T2 patients, the 5-year overall survival rate of patients with HLC was not different from that of the CBDC patients. In contrast, in the $\mathrm{T} 3$ patients, the 5-year survival rate of the HLC patients was $15.5 \%$ and that of the CBDC patients was 59.5 percent. The difference was statistically significant ( $p=0.043$ ) (Fig. 2). The 5-year overall survival rate of HLC in N0 patients was $28.6 \%$ and that of the CBDC patients was 70.0 percent. The rates were statistically significant $(p=0.001)$. In the N1 patients, the 5-year overall survival rate in patients with HLC was $14.1 \%$ and was not statistically different from CBDC, which was 29.3 percent (Fig. 3).

In the R0 resection patients, the 5-year overall survival rate of patients with HLC was $19.8 \%$ and that of CBDC was $55.5 \%$, which was significantly different $(p=0.019)$. The 5-year overall survival rates of HLC and CBDC were not statistically different in patients with $\mathrm{R} 1$ resections

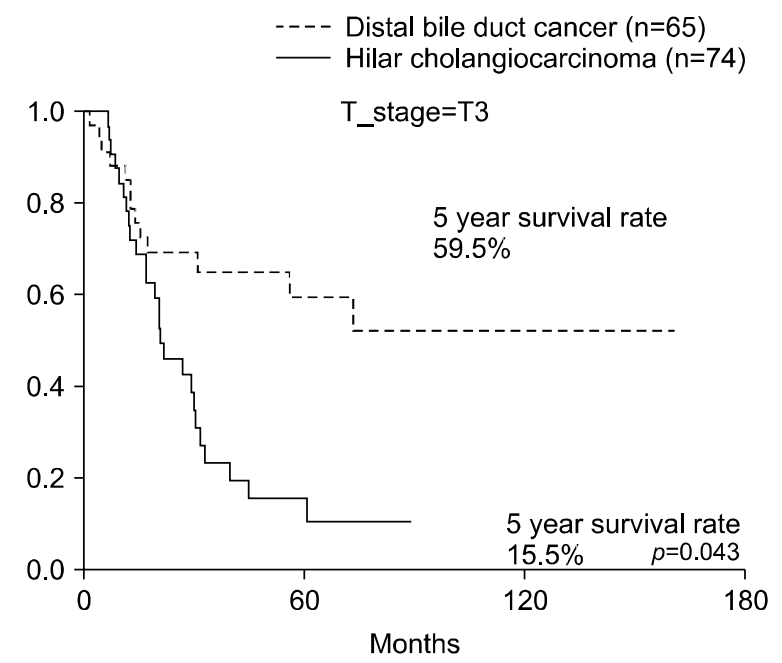

Fig. 2. Comparison of the overall-survival rates between hilar cholangiocarcinoma and distal bile duct cancer according to $\mathrm{T}$ stages. 

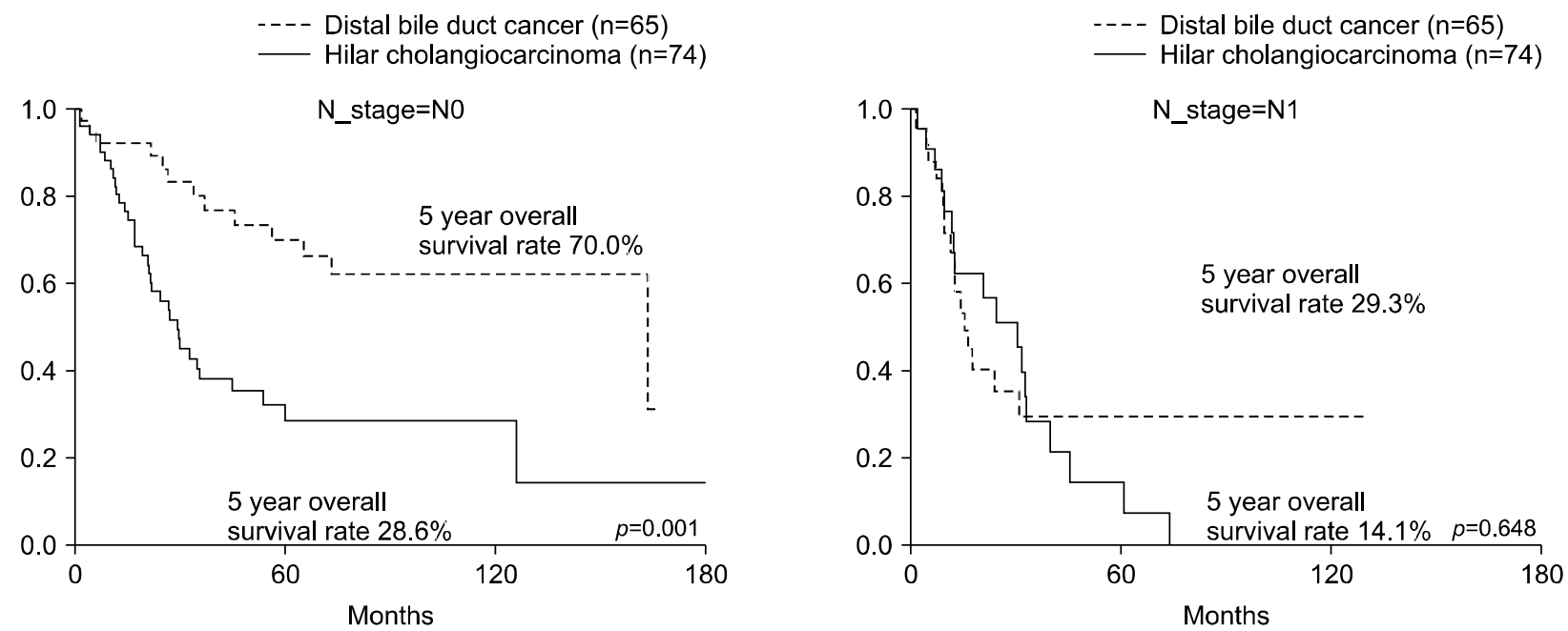

Fig. 3. Comparison of the overall-survival rates between hilar cholangiocarcinoma and distal bile duct cancer according to $\mathrm{N}$ stages.
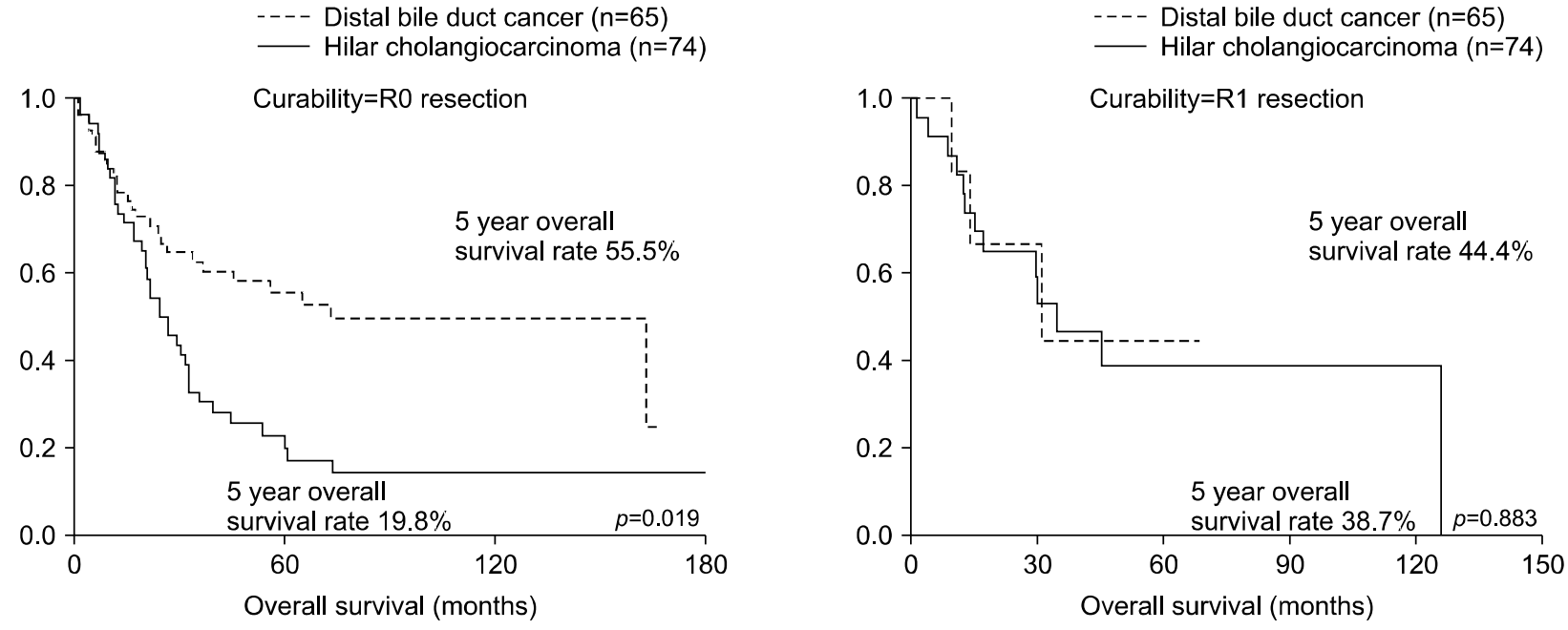

Fig. 4. Comparison of the overall-survival rates between hilar cholangiocarcinoma and distal bile duct cancer according to R0/R1 resections.

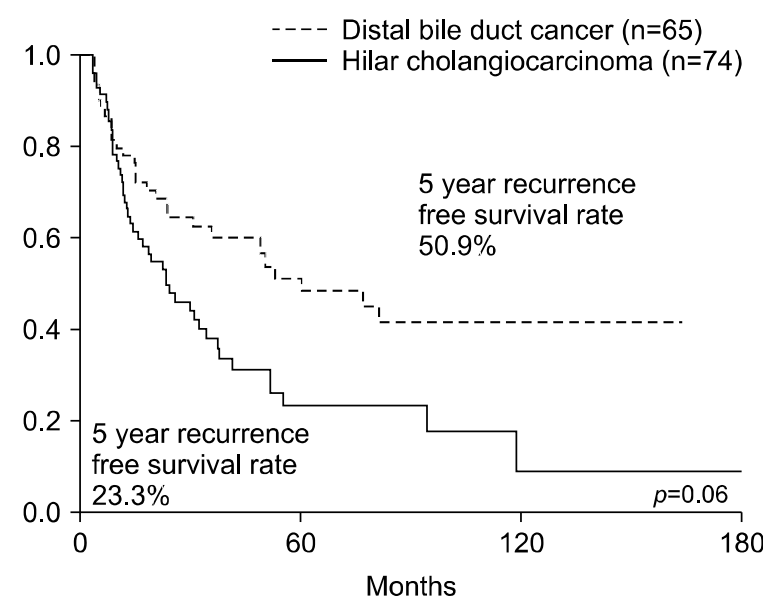

Fig. 5. Comparison of the recurrence-free survival rates between hilar cholangiocarcinoma and distal bile duct cancer according to cancer location (T2/T3).
(Fig. 4).

The 5-year recurrence-free survival rate of HLC was $23.3 \%$ and this was lower than that of the CBDC patients, but this difference was not statistically significant ( $p=$ 0.06 ) (Fig. 5). The 5-year recurrence-free survival rate of T2 HLCs was $26.6 \%$ and that of the CBDC T2 group was $47.1 \%$, but the difference was not statistically significant $(p=0.300)$. The 5-year recurrence-free survival rate of $\mathrm{T} 3$ HLC was $23.1 \%$, and that of distal bile duct cancer was $55.7 \%$, but the difference was not statistically significant ( $p=0.102)$ (Fig. 6). In N0 patients, the 5-year recurrencefree survival rate based on cancer location was statistically significant $(p=0.001)$, with a 5 -year recurrence-free survival rate of $23.2 \%$ for HLC patients, while that for 

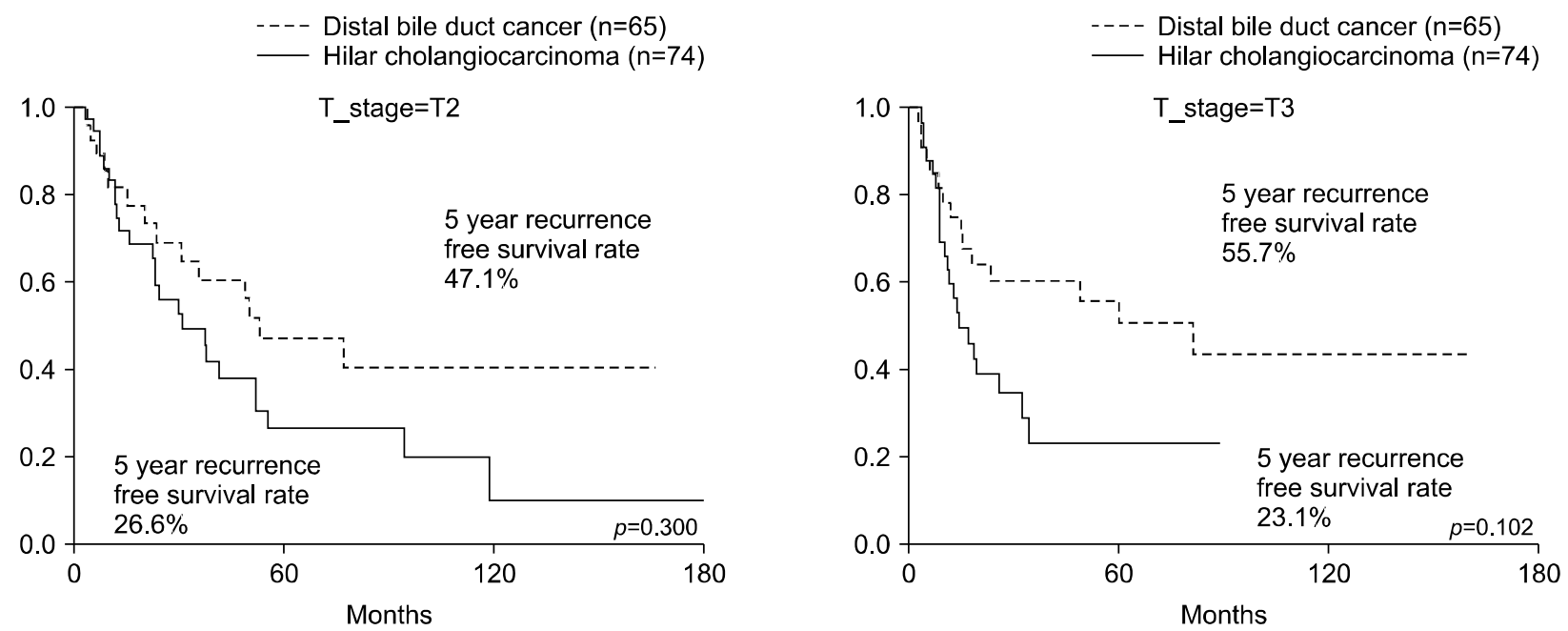

Fig. 6. Comparison of recurrence-free survival rates between hilar cholangiocarcinoma and distal bile duct cancer according to $\mathrm{T}$ stages.
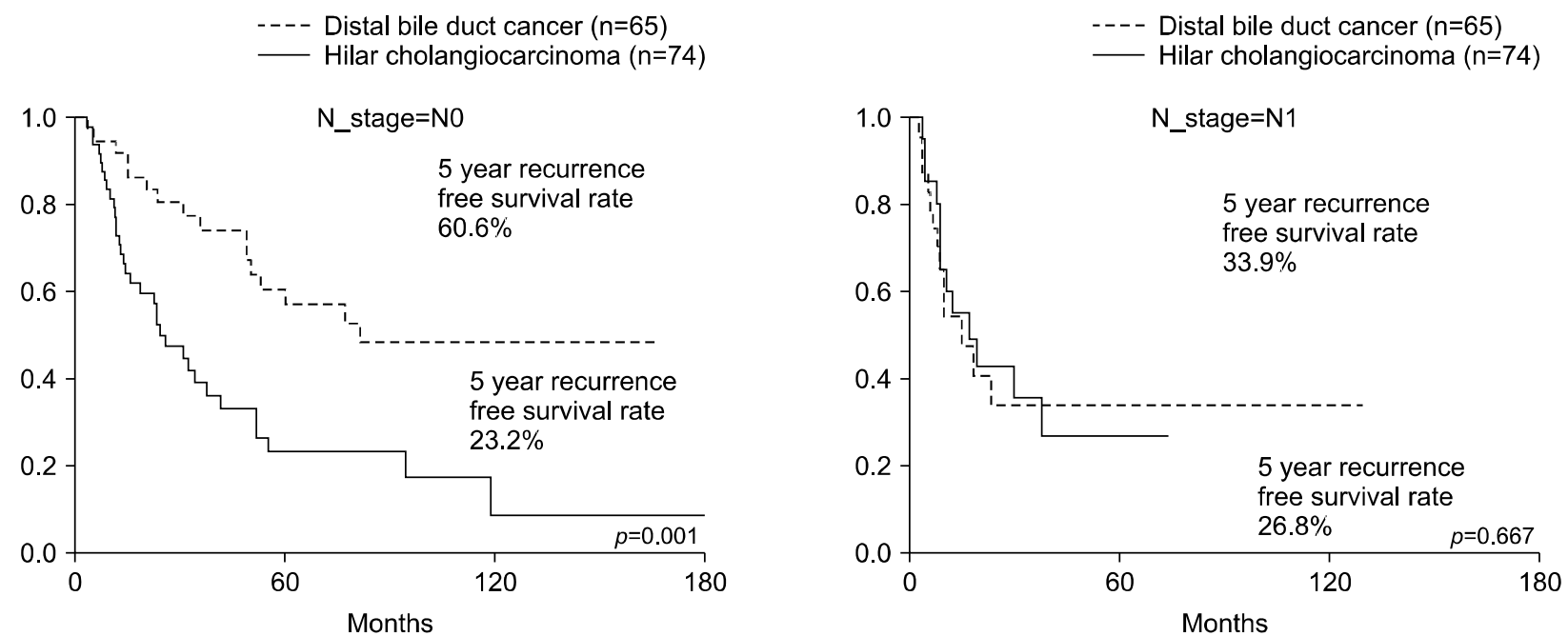

Fig. 7. Comparison of the recurrence-free survival rates between hilar cholangiocarcinoma and distal bile duct cancer according to $\mathrm{N}$ stages.
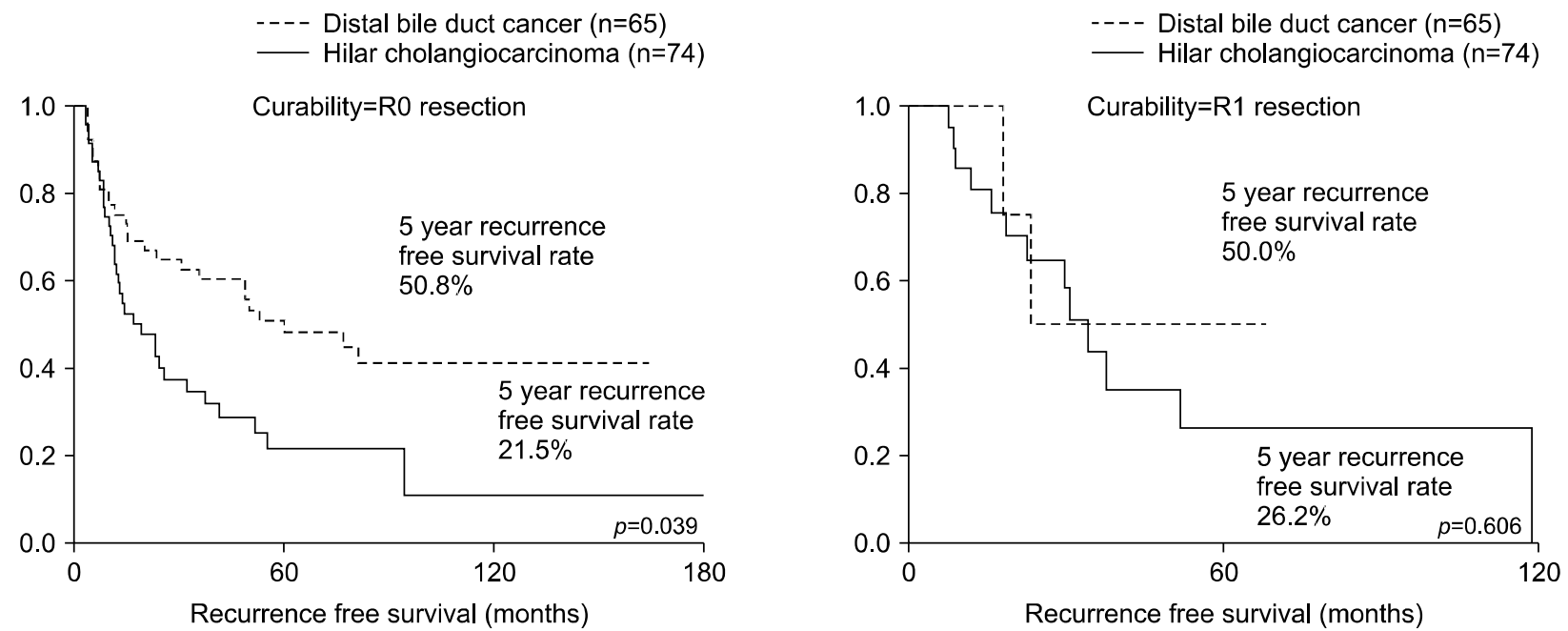

Fig. 8. Comparison of the recurrence-free survival rates between hilar cholangiocarcinoma and distal bile duct cancer according to $\mathrm{R} 0 / \mathrm{R} 1$ resections. 
Table 2. Multivariate analysis of prognostic factors for overall and recurrence-free survival of all patients

\begin{tabular}{lrc}
\hline & $p$ value & \multicolumn{1}{c}{$95 \%$ CI } \\
\hline Overall survival & & \\
$\mathrm{N}$ stage & $<0.001$ & $1.640-4.507$ \\
Tumor site & 0.004 & $0.271-0.779$ \\
Recurrence free survival & & \\
$\mathrm{N}$ stage & 0.009 & $1.188-3.294$ \\
Tumor site & 0.038 & $0.357-0.971$ \\
\hline
\end{tabular}

CBDC patients was 60.6 percent. The 5-year recurrencefree survival of patients with HLC and CBDC did not differ significantly in N1 patients $(p=0.667)$ (Fig. 7).

In the $\mathrm{R} 0$ resection patients, the 5-year recurrence-free survival rate of the HLC patients was $21.5 \%$ and that of the CBDC patients was $50.8 \%$, which was statistically significant $(p=0.039)$. The 5-year recurrence-free survival rates of $\mathrm{R} 0$ patients in the HLC and CBDC groups were not significantly different (Fig. 8).

Multivariate analysis revealed that lymph node metastases and hilar tumor locations were independent poor prognostic factors for both the overall and recurrence-free survival rates in these patients (Table 2).

\section{DISCUSSION}

Occasionally, extrahepatic bile duct cancer is found at an advanced stage. ${ }^{12,13}$ Surgical removal of the extrahepatic bile duct cancer ensures the highest survival rate, so surgery should be considered whenever possible. ${ }^{14}$ Previous studies have suggested that the factors affecting recurrence and survival after the surgical resection of extrahepatic bile duct cancer are invasion to adjacent organs; perineural invasion; lymphovascular invasion; lymph node metastasis; TMN stage; alkaline phosphatase, total bilirubin, direct bilirubin, aspartate aminotransferase, alanine aminotransferase, and gamma-glutamyl transferase levels; tumor differentiation status and blood transfusions. ${ }^{15,16}$ The results of adjuvant treatment for extrahepatic bile duct cancer, such as chemotherapy and radiotherapy, are not satisfactory. ${ }^{17}$ But a few recent studies showed a slight survival gain. ${ }^{18}$ Gabriel et al. ${ }^{19}$ reported that gemcitabine plus cisplatin for biliary cancer provided survival benefit. Moureau-Zabotto et al. reported that the conformal-3D external-beam-radiotherapy (EBRT) seemed efficient to treat locally-advanced and unresectable extrahepatic cholangio- carcinomas, with acceptable toxicity. ${ }^{20}$

Many studies have demonstrated that the prognosis for HLC was worse than that for CBDC. ${ }^{21,22}$ Park et al. ${ }^{23}$ reported that the 5-year survival rate of patients with extrahepatic cholangiocarcinoma, on the site of the tumor, were higher in CBDC. The histologic structure of the extrahepatic bile duct can be different depending on its location. In the hilar area, the muscle fiber is scattered. But the distal bile duct consists of smooth muscle bundles. Although differences in the degree of tumor invasion have been investigated, the fibromuscular, subserosa, and serosa layers are very thin histologically, therefore, it is difficult to distinguish the infiltration limit between them. ${ }^{24}$ Differences in local invasion or lymph node metastases due to these anatomical and histologic differences may lead to differences in survival rates but currently, there is no definitive consensus in the literature. Baek et al. reported that there was no difference in prognosis related to the location of bile duct cancer and that R0 resection was the most important factor affecting prognosis. ${ }^{25}$

In our study, a total of 281 patients underwent surgery for extrahepatic cholangiocarcinomas. However, the number of patients with $\mathrm{T} 1$ was small and curative resections frequently could not be performed in the patients with T4. Therefore, we selected patients with only T2 and T3 stage cancers who underwent successful resection for our study. In this study, a hilar location of the cholangiocarcinoma was an independent poor prognostic factor.

In R0 resected patients with HLC, the prognosis was poorer than for those with CBDC. In R1 resected patients, the prognosis was poor and not different between HLC and CBDC patients. The rate of $\mathrm{R} 1$ resection was higher in HLC patients. The rate of transfusion was higher in hilar cholangiocarcinoma patients. When multivariate analysis was performed, tumor site (hilar location of cholangiocarcinoma) and lymph node metastases were independent poor prognostic factors. R1 resection was not an independent prognostic factor.

Lymph node metastasis is well known as an important prognostic factor affecting survival or recurrence in patients with extrahepatic bile duct cancer. Choi et al. reported that the 5 -year survival rate was $50.4 \%$ in patients who had no lymph node metastases compared to a $13.0 \%$ 5 -year survival rate in patients with lymph node metastases. $^{26}$ Yoshida et al. ${ }^{27}$ also reported that lymph node 
stage was an independent prognostic factor. Patients with up to two positive lymph nodes had a more favorable prognosis than that of other patients. The authors recommended pancreaticoduodenectomies with extended lymphadenectomies and adjuvant chemotherapy for the treatment of patients with CBDC. Kitagawa et al. ${ }^{28}$ analyzed the patterns of lymph node metastases of HLC and emphasized that aggressive lymphadenectomy was necessary because the pericholedocal node was the most common site of lymph node metastasis and that metastasis occurred along the lymphatic drainage system. Patients with lymph node metastases also had significantly lower overall survivals and recurrence-free survivals in this study.

This study revealed that the prognosis for HLC patients was worse than for CBDC patients under curative surgical conditions. However, in cases of lymph node metastases or $\mathrm{R} 1$ resections, the prognosis was poor and not different between patients with HLC or CBDC.

In conclusion, we should do our best to perform R0 resections to achieve better prognoses. The development of new adjuvant treatment methods for extrahepatic bile duct cancers with lymph node metastases is necessary. Further studies into the cause of the differences in survival rates between HLC and CBDC patients are needed.

\section{ACKNOWLEDGEMENTS}

This study was supported by a grant from the Korea Institute of Radiological and Medical Sciences (KIRAMS), funded by the Ministry of Science and ICT (MSIT), Republic of Korea (No.50541-2019).

\section{REFERENCES}

1. Vauthey JN, Blumgart LH. Recent advances in the management of cholangiocarcinomas. Semin Liver Dis 1994;14:109-114.

2. Kang HJ, Kwon SJ, Kwon TW, Kim GS, Kim NG, Kim DW, et al. Liver, GB, biliary, pancreas, spleen. In: Korean Surg Soc, ed. Surgery. 2nd ed. Seoul: Gunja, 2017:760.

3. Jung KW, Won YJ, Kong HJ, Lee ES; Community of PopulationBased Regional Cancer Registries. Cancer statistics in Korea: incidence, mortality, survival, and prevalence in 2015. Cancer Res Treat 2018;50:303-316.

4. Lee HG, Lee SH, Yoo DD, Paik KY, Heo JS, Choi SH, et al. Carcinoma of the middle bile duct: is bile duct segmental resection appropriate? World J Gastroenterol 2009;15:5966-5971.

5. Kloek JJ, Ten Kate FJ, Busch OR, Gouma DJ, van Gulik TM. Surgery for extrahepatic cholangiocarcinoma: predictors of survival. HPB (Oxford) 2008;10:190-195.
6. Marcano-Bonilla L, Mohamed EA, Mounajjed T, Roberts LR. Biliary tract cancers: epidemiology, molecular pathogenesis and genetic risk associations. Chin Clin Oncol 2016;5:61.

7. Park JY, Kim HH, Park EK, Seoung JS, Hur YH, Koh YS, et al. Histopathologic prognostic factors for recurrence and survival after surgical resection of middle and distal bile duct cancer. Korean J Hepatobiliary Pancreat Surg 2010;14:166.

8. Cidon EU. Resectable cholangiocarcinoma: reviewing the role of adjuvant strategies. Clin Med Insights Oncol 2016;10:43-48.

9. Vern-Gross TZ, Shivnani AT, Chen K, Lee CM, Tward JD, MacDonald OK, et al. Survival outcomes in resected extrahepatic cholangiocarcinoma: effect of adjuvant radiotherapy in a surveillance, epidemiology, and end results analysis. Int J Radiat Oncol Biol Phys 2011;81:189-198.

10. Wakai T, Shirai Y, Moroda T, Yokoyama N, Hatakeyama K. Impact of ductal resection margin status on long-term survival in patients undergoing resection for extrahepatic cholangiocarcinoma. Cancer 2005;103:1210-1216.

11. Kim JW, Jo S, Moon HJ, Heo JS, Choi SH, Joh JW, et al. Prognostic factors after major resection for distal extrahepatic cholangiocarcinoma. Korean J Gastroenterol 2006;47:144-152.

12. Lee J, Koh DH. Molecular pathogenesis and the role of tumor markers in cholangiocarcinoma. Korean J Med 2010;79:597-604.

13. Ryu, JK. The epidemiology and risk factors of hilar cholangiocarcinoma. Korean J Med 2010;79:593-596.

14. Patel T. Cholangiocarcinoma--controversies and challenges. Nat Rev Gastroenterol Hepatol 2011;8:189-200.

15. Eun JR, Jang BI, Lee JY, Kim KO, Lee SH, Kim TN, et al. Clinical characteristics of intrahepatic cholangiocarcinoma and prognostic factors in patients who received non-surgical treatment. Korean J Gastroenterol 2009;54:227-234.

16. Mao ZY, Guo XC, Su D, Wang LJ, Zhang TT, Bai L. Prognostic factors of cholangiocarcinoma after surgical resection: a retrospective study of 293 patients. Med Sci Monit 2015;21:2375-2381.

17. Howell M, Valle JW. The role of adjuvant chemotherapy and radiotherapy for cholangiocarcinoma. Best Pract Res Clin Gastroenterol 2015;29:333-343.

18. Ramírez-Merino N, Aix SP, Cortés-Funes H. Chemotherapy for cholangiocarcinoma: an update. World J Gastrointest Oncol 2013; 5:171-176.

19. Gabriel E, Gandhi S, Attwood K, Kuvshinoff B, Hochwald S, Iyer R. Gemcitabine and capecitabine for advanced biliary cancer. J Gastrointest Oncol 2017;8:728-736.

20. Moureau-Zabotto L, Turrini O, Resbeut M, Raoul JL, Giovannini $\mathrm{M}$, Poizat $\mathrm{F}$, et al. Impact of radiotherapy in the management of locally advanced extrahepatic cholangiocarcinoma. BMC Cancer 2013;13:568.

21. Blom D, Schwartz SI. Surgical treatment and outcomes in carcinoma of the extrahepatic bile ducts: the University of Rochester experience. Arch Surg 2001;136:209-215.

22. Reding R, Buard JL, Lebeau G, Launois B. Surgical management of 552 carcinomas of the extrahepatic bile ducts (gallbladder and periampullary tumors excluded). Results of the French surgical association survey. Ann Surg 1991;213:236-241.

23. Park SW, Park YS, Chung JB, Kang JK, Kim KS, Choi JS, et al. Patterns and relevant factors of tumor recurrence for extrahepatic bile duct carcinoma after radical resection. Hepatogastroenterology 2004;51:1612-1618.

24. Kim HJ, Bang S, Park SW, Song SY, Kim KS, Lee WJ, et al. Assessment of the definition of early extrahepatic bile duct cancer through the prognosis analysis who had received curative resection. Korean J Gastroenterol 2007;50:101-107.

25. Baek JO, Kim YH, Kang GJ, IM TJ. Comparison of survival rates according to tumor location and surgical method in patients 
with extrahepatic bile duct cancer treated with curative resection. Paper presented at: 32st Korean hepatobiliarypancreas surgery symposium; 2010 Mar 26-27; Seoul, Korea. p. 133.

26. Choi SB, Park SW, Kim KS, Choi JS, Lee WJ. The survival outcome and prognostic factors for middle and distal bile duct cancer following surgical resection. J Surg Oncol 2009;99:335342.

27. Yoshida T, Matsumoto T, Sasaki A, Morii Y, Aramaki M, Kitano
S. Prognostic factors after pancreatoduodenectomy with extended lymphadenectomy for distal bile duct cancer. Arch Surg 2002;137: 69-73.

28. Kitagawa Y, Nagino M, Kamiya J, Uesaka K, Sano T, Yamamoto $\mathrm{H}$, et al. Lymph node metastasis from hilar cholangiocarcinoma: audit of 110 patients who underwent regional and paraaortic node dissection. Ann Surg 2001;233:385-392. 